
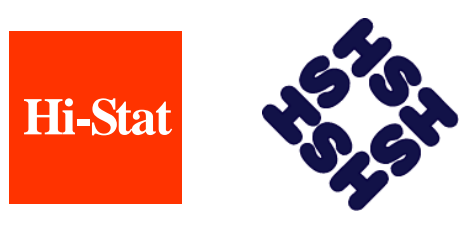

Discussion Paper Series

No.226

\title{
Weather Risk, Wages in Kind, and the Off-Farm \\ Labor Supply of Agricultural Households \\ in a Developing Country
}

Takahiro Ito

Takashi Kurosaki

November 2007

Hitotsubashi University Research Unit for Statistical Analysis in Social Sciences

A 21st-Century COE Program

Institute of Economic Research

Hitotsubashi University

Kunitachi, Tokyo, 186-8603 Japan

http://hi-stat.ier.hit-u.ac.jp/ 


\title{
Weather Risk, Wages in Kind, and the Off-Farm Labor Supply of Agricultural Households in a Developing Country*
}

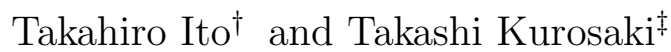

7 November 2007

\begin{abstract}
This paper investigates the effects of weather risk on the off-farm labor supply of agricultural households in a developing country. Faced with the uninsurable risk of output and food price fluctuations, poor farmers in developing countries may diversify labor allocation across activities in order to smooth income in real terms. A key feature of this paper is that it distinguishes different types of off-farm labor markets: agriculture and non-agriculture on the one hand, and, wages paid in cash and wages paid in kind on the other. We develop a theoretical model of household optimization, which predicts that when farmers are faced with more production risk in their farm production, they find it more attractive to engage in non-agricultural work as a means of risk diversification, but the agricultural wage sector becomes more attractive when food security is an important issue for the farmers and agricultural wages are paid in kind. To test this prediction, we estimate a multivariate two-limit tobit model of labor allocation using household data from rural areas of Bihar and Uttar Pradesh, India. The regression results show that the share of the off-farm labor supply increases with weather risk, the increase is much larger in the case of non-agricultural work than in the case of agricultural wage work, and the increase is much larger in the case of agricultural wages paid in kind than in the cash wage case. Simulation results based on the regression estimates show that the sectoral difference is substantial, implying that empirical and theoretical studies on farmers' labor supply response to risk should distinguish between the types of off-farm work involved.
\end{abstract}

JEL classification codes: Q12, O15, J22.

Keywords: covariate risk, non-farm employment, self-employment, food security, India.

${ }^{*}$ This is a thoroughly revised version of the COE Discussion Paper no.161, titled "Weather Risk and the Off-Farm Labor Supply of Agricultural Households in India," April 2006. The authors are grateful to Nobuhiko Fuwa, Stefan Klonner, Daiji Kawaguchi, and the participants of the 2006 IAAE Conference for their useful comments on earlier versions of this paper. All remaining errors are ours.

${ }^{\dagger}$ Graduate School of Economics, Hitotsubashi University. E-mail: ed044001@srv.cc.hit-u.ac.jp

${ }^{\ddagger}$ Corresponding author. The Institute of Economic Research, Hitotsubashi University, 2-1 Naka, Kunitachi, Tokyo 186-8603 Japan. Phone: 81-42-580-8363; Fax.: 81-42-580-8333. E-mail: kurosaki@ier.hit-u.ac.jp. 


\section{Introduction}

This paper investigates the effects of weather risk on the off-farm labor supply of agricultural households in a developing country. In low-income developing countries like India, markets for agricultural inputs and outputs are well-developed, while the development of credit and insurance markets has been lagging behind (Townsend, 1994; Kochar, 1997a; 1997b). This means that people in general, and particularly poor farmers, have few means to hedge against the vagaries of production and price shocks that may put their livelihood at risk (Fafchamps, 2003; Dercon, 2005). It has long been argued that poor farmers in developing countries attempt to minimize their exposure to risk by growing their own necessities (Fafchamps, 1992; Kurosaki and Fafchamps, 2002), diversifying their activities (Walker and Ryan, 1990; Kurosaki, 1995), and through other income smoothing measures. If risk avoidance inhibits gains from specialization and prevents farmers from achieving the output potential they would be capable of, the provision of efficient insurance mechanisms becomes highly important in poverty reduction policies.

As an example of such inefficiency due to risk avoidance, we focus on the labor supply of farmers in developing countries. In the development literature, the relationship between risk and labor market participation has been analyzed by several authors. For example, Kochar (1999) and Cameron and Worswick (2003) examined the role of labor market participation as an ex post risk-coping mechanism for households hit by idiosyncratic shocks, such as injury or plot-level crop failure. The two studies showed that additional wage income was critically important for shock-hit households in India (Kochar) and in Indonesia (Cameron and Worswick) to maintain consumption levels. Rose (2001) focused on the role of labor market participation both as an ex ante and an ex post response to covariate shocks. She showed that households facing a greater risk in terms of the reliability of rainfall were more likely to participate in the labor market (ex ante response). Moreover, unexpectedly bad weather and low rainfall also increased labor market participation (ex post response). Finally, Townsend (1994) showed that Indian villagers found it more difficult to insure against covariate risk than against idiosyncratic risk.

Taking these findings as our point of departure, we argue that in low-income developing 
countries, it is important to distinguish different types of off-farm labor markets: agriculture and non-agriculture on the one hand, and, wages paid in cash and wages paid in kind on the other. Rose's (2001) analysis simply considered a single labor market outside the farm, which, however, raises the following problems. First, the covariance between farming returns and agricultural wages is likely to be different from the covariance between farming returns and non-agricultural wages. When an area is hit by bad weather, this may lead to a decline not only in a farmer's own farm income but also reduce the demand for agricultural labor outside the farm, resulting in a high covariance between own-farm returns and wages available from agricultural work. In contrast, wages outside agriculture are likely to be less correlated with own-farm returns because they are less likely to be affected by the same kind of shocks. This line of reasoning suggests that agricultural households would find it more attractive to engage in non-agricultural work as a means of ex ante risk diversification. Second, the covariance between wages and food prices also matters in determining the level of real income (Fafchamps, 1992; Kurosaki and Fafchamps, 2002; Kurosaki, 2006). For farmers for whom food security is an issue, agricultural work may nevertheless be more attractive than nonagricultural work if agricultural wages are paid in kind, since the monetary value of wages paid in paddy (the staple crop) is positively correlated with the paddy price. This paper shows that both of these considerations do indeed play a role in determining the off-farm labor supply of farmers in a developing country.

The remainder of the paper is organized as follows. In Section 2, we present a theoretical model to explain how farmers decide to allocate their labor, incorporating considerations of food security. We test the predictions of the model using household data from two Indian states, Bihar and Uttar Pradesh. The dataset is described in Section 3, while the regression results of a multivariate two-limit tobit model of labor allocation are presented in Section 4. The results robustly show that the share of the off-farm labor supply increases with weather risk, the increase is much larger in the case of non-agricultural work than in the case of agricultural wage work, and the increase is much larger in the case of agricultural wages paid in kind than in the cash wage case. Section 5 shows simulation results based on the regression estimates in order to examine whether the sectoral difference is economically significant. Section 6 concludes the paper. 


\section{A Theoretical Model of Labor Allocation}

In this section, we present a theoretical model to guide our empirical analysis. Throughout the section, we assume a unitary decision making process at the household level with respect to labor allocation (Singh et al., 1986). ${ }^{1}$ To stylize the conditions of low-income developing countries, we assume that there are only two consumption items: "food," which is the main output in production and the main item in consumption; and "non-food," whose price is normalized at one. The food price is $p\left(=\theta_{p} \bar{p}\right)$, where $\theta_{p}$ is the multiplicative price risk with a mean of one.

For simplicity, we fix the total labor supply at $\bar{L}$, ignoring the labor-leisure choice. The welfare of the household is measured by its expected utility, which is defined as $E[v(y, p)]$ with the following properties:

$$
v_{y}>0, \quad v_{p}<0, \quad v_{y y}<0, \quad v_{p p}<0, \quad v_{y p}>0, \quad v_{y y y}>0 .
$$

The first two properties are required for a valid indirect utility function. The third property guarantees that the household is risk-averse in the Arrow-Pratt sense, and the fourth implies that, for a given income level, the household's welfare decreases when the food price variability increases. The fourth property is especially appropriate for a (potentially) food-insecure household in a developing country (Kurosaki, 2006). The last assumption, $v_{y y y}>0$, corresponds to "risk prudence," which is required for the welfare cost of consumption fluctuations to decrease with the level of expected consumption (Kimball, 1990). In effect, these assumptions guarantee that the household behaves in a risk-averse and prudent way with respect to income variability, suffers if food price variability is higher, and gains if the correlation between the food price and income is higher. ${ }^{2}$

There are four different types of activity to which the household can allocate labor $\bar{L}$ (indicated by subscript $j$ ): own farming $(j=a)$, agricultural wage work paid in cash $(j=b)$, agricultural wage work paid in kind $(j=c)$, and non-agricultural wage work $(j=d)$. We

\footnotetext{
${ }^{1}$ This assumption is based on our preliminary result from various demographic and health surveys in the world that bargaining issues are less important in South Asia than in Sub-Saharan Africa. Extending the analysis of this paper under a non-unitary household modeling framework and empirically testing whether bargaining among members within a household is important in the current dataset are left for further study.

${ }^{2}$ Note that when the food price and nominal income are positively correlated, real income is more stable.
} 
assume that non-agricultural wages are always paid in cash. Since the total labor supply is fixed, the decision variables are the shares of each type of labor $\left(\ell_{j}\right)$. From each activity, the household obtains a labor return of $\theta_{j} f_{j}\left(\ell_{j} \bar{L}\right)$, where $\theta_{j}$ is the multiplicative risk at the local level with a mean of one, and $f($.$) is a function characterizing the expected value of the labor$ return. Function $f($.$) is likely to be linear for wage work outside the farm while it is likely$ to be concave for own farming. Thus, the household's optimization problem is expressed as:

$$
\max _{\ell_{j}} E\left[v\left(y, p, X_{p}\right)\right]
$$

subject to the budget constraint

$$
y=y_{0}+\sum_{j} \theta_{j} f_{j}\left(\ell_{j} \bar{L}, X_{w}\right)
$$

the time constraint

$$
\sum_{j} \ell_{j}=1
$$

and the non-negativity conditions for $\ell_{j}, j=a, b, c, d . X_{p}$ and $X_{w}$ are vectors of household characteristics: $X_{p}$ includes shifters of preferences with respect to risk exposure and food subsistence needs, while $X_{w}$ includes shifters of household members' productivity, such as land, fixed capital, and human capital. $y_{0}$ denotes unearned income.

The first order conditions for the interior solution to this optimization problem are as follows:

$$
E\left[v_{y} \theta_{j}\right] \frac{\partial f_{j}}{\partial L}=E\left[v_{y} \theta_{k}\right] \frac{\partial f_{k}}{\partial L}, \quad j \neq k,
$$

where $\partial f_{j} / \partial L=\partial f_{j} / \partial\left(\ell_{j} \bar{L}\right)$, which is the expected value of the marginal labor return on activity $j$. When there is no risk, or there is risk but $v_{y}$ and $\theta_{j}$ are independent for all $j$, equation (5) reduces to the familiar condition that marginal returns are equilibrated across activities. This is unlikely, however, when there is risk - we expect $v_{y}$ and $\theta_{j}$ to be negatively correlated through the budget constraint (3) and due to the assumption of $v_{y y}<0$.

Applying the implicit function theorem to (5), we obtain the reduced-form optimal solution as

$$
\ell_{j}^{*}=\ell_{j}\left(\bar{L}, X_{p}, X_{w}, \Sigma\right), \quad j=a, b, c, d,
$$


where $\Sigma$ is the covariance matrix of $\theta_{a}, \theta_{b}, \theta_{c}, \theta_{d}$, and $\theta_{p}$. To stylize typical situations in rural India, the theoretical discussion assumes the following: (i) non-agricultural wages are not correlated with farm income, agricultural wages, and the food price; (ii) farm income and agricultural wages are positively correlated, and the correlation is greater when wages are paid in kind (i.e. food) than when wages are paid in cash; and (iii) agricultural wages and the food price are positively correlated, and the correlation is greater when wages are paid in kind than when wages are paid in cash. Under these assumptions, it is likely that the optimal labor choice satisfies the following relations:

$$
\frac{\partial \ell_{a}^{*}}{\partial \sigma_{a}}<0, \quad \frac{\partial \ell_{c}^{*}}{\partial \sigma_{a}}>\frac{\partial \ell_{b}^{*}}{\partial \sigma_{a}}, \quad \frac{\partial \ell_{d}^{*}}{\partial \sigma_{a}}>\frac{\partial \ell_{b}^{*}}{\partial \sigma_{a}},
$$

where $\sigma_{a}$ is the coefficient of variation of $\theta_{a}$ (see Appendix I for the derivation).

The first relation in (7) implies that the own-farm labor supply declines as production becomes riskier. In other words, farmers find it more attractive to engage in off-farm work as a means of ex ante diversification under riskier farming conditions. However, the alternatives to own-farm work are not homogeneous. The second and third relations in (7) imply that it is agricultural wage work paid in kind and non-agricultural wage work that absorb a larger share of the displaced labor. This is what we empirically test in Section 4 .

The reason why agricultural wage work paid in kind is more attractive to farmers than agricultural wage work paid in cash is as follows. When the food price fluctuates, what matters to farmers is not the level or stability of nominal income but the level and stability of real income. Since the food price and shocks to labor returns are not independent, the labor allocation may affect the level and stability of food-insecure farmers' real income through the covariance between the food price and shocks to labor returns (Fafchamps, 1992). Since wage levels are usually rigid, the correlation is expected to be close to zero when the agricultural wage is paid in cash, while it is expected to be positive when the wage is paid in kind (Kurosaki, 2006). As the second relation in (7) shows, agricultural work paid in kind is more attractive than agricultural work paid in cash because of the difference in the correlation. Thus, as an empirically verifiable prediction, we test whether the effect of $\sigma_{a}$ on the labor supply share to agricultural wage work paid in kind is larger than that on the labor share to agricultural wage work paid in cash. 


\section{Data}

\subsection{Household Data on Labor Allocation}

In the empirical part of this paper, we use data obtained from the Survey of Living Conditions, Uttar Pradesh and Bihar, which is one of the Living Standard Measurement Study (LSMS) surveys conducted in developing countries with technical guidance from the World Bank. Uttar Pradesh (UP) and Bihar are located in the Ganges Plain of North India and are known for their high incidence of poverty. The survey was conducted in 1997/98 and covers 1,035 households from 57 villages in 13 districts of Bihar and 1,215 households from 63 villages in 12 districts of UP. To focus on the labor allocation of agricultural households, households operating no farmland and households with missing information on labor were excluded from our analysis (the number of excluded households is 580). The sample used in this paper thus comprises owner farm households, owner-cum-tenant farm households, and pure tenant households. Information on working days per month and average working hours per day is available for each household member from January 1997 to December 1997. From this information, we compile the household-level data on the amount of labor allocated to each of the following five activities: (a) self-employment in agriculture, (b) wage work in agriculture paid in cash, (c) wage work in agriculture paid in kind, (d) wage work in non-agriculture, and (e) self-employment in non-agriculture.

Based on these five activities, we divide patterns of labor allocation into five categories (Table 1). Among the five categories, category A, households relying on self-employed work only, make up the largest group, accounting for $41.4 \%$ of the total, followed by households that combine own farming with wage work (pattern C, 36.4\%). Yet, off-farm labor is clearly important for agricultural households: $58.6 \%$ of households had one or more family members that were engaged in wage work in agriculture or non-agriculture ('Including (b), (c), or (d)' in the table). The table also shows that work in non-agriculture was more frequent than work in agriculture (48.3\% versus $28.4 \%$ of households).

Table 2 shows the household characteristics arranged by the three typical patterns of labor allocation. Comparing the second row titled 'Self-employment only' with the other rows, we see that farm households with income sources other than own farming have less farmland. 
For households with only small landholdings relative to the number of household members, it is difficult to make a living based on farming alone. Such households consequently allocate more labor to off-farm work. Similar findings have been reported for India as a whole based on nation-wide surveys in 1999/2000 (NSSO, 2000) and 1993/94 data collected by the National Centre of Applied Economic Research (Lanjouw and Shariff, 2004).

The column titled 'Annual labor supply' in Table 2 also shows that pure farm households ('Self-employment only') supply the smallest amount of labor per household. By dividing 'Annual labor supply' by 'No. of working members,' we can obtain the total labor supply per person. Pure farm households still supply the smallest amount of labor per person. According to the standard agricultural household model (Singh et al., 1986), the smaller labor supply of these farm households indicates that their reservation wage is higher than that of other households because these farm households have larger landholdings.

\subsection{District Data on Rainfall and the Estimation of Covariate Risk}

In order to empirically test the theoretical predictions, we need a proxy for $\sigma_{a}$ (the coefficient of variation of local production shocks in farming). As the proxy variable, we compile the coefficient of variation of annual rainfall at the district level. The data source is Johnson et al. (2003). To confirm that the variation of rainfall is a relevant proxy, we regress rice production on rainfall and other explanatory variables. The source for our data on rice production is GOI (2001).

Table 3, column 1 reports the results of this regression. To control for differences in topology, land fertility, and other agro-ecological factors, district fixed effects are included. The effect of rainfall on rice production is positive and statistically significant at the $1 \%$ level: an increase in rainfall by one standard deviation raises rice production by 11,300 tons. Our rainfall variable is thus a good proxy for the rice production risk. In addition, rice production and the agricultural value-added at the state level are highly correlated, with a time-series correlation coefficient of 0.85 for Bihar and 0.97 for UP. Therefore, our rainfall variable is a valid proxy for the agricultural production risk at the district level.

In order to verify the validity of the assumptions (i) and (ii) in the theoretical model (non-agricultural wages are not correlated with farm income, while agricultural wages are 
positively correlated), we also regress daily wage rates of plowmen and carpenters on rainfall (Table 3, columns 2 and 3). The data source on wage rates is GOI (1991-2000). After controlling for district heterogeneity by district fixed effects and controlling for fluctuation in prices by year dummies, the effect of rainfall on market wages is positive in both models, but only the effect on agricultural wages is statistically significant at $10 \%$ level. The magnitude of the coefficient is considerably (approximately six times) larger than the magnitude of the coefficient in the non-agricultural wage regression. Therefore, our assumptions are validated by the data.

\subsection{Description of Variables}

Summary statistics of the variables used in the regression analysis are presented in Table 4. The dependent variables are the shares of the different types of work: own farming $(j=a)$, agricultural wage work paid in cash $(j=b)$, agricultural wage work paid in kind $(j=c)$, non-agricultural wage work $(j=d)$, and own business in non-agriculture $(j=e)$. Since the five shares add up to $100 \%$ by definition, we drop the last category, self-employment in non-agriculture, in the regression analysis below.

Adopting a reduced-form approach, we regress the four dependent variables on household characteristics $(X)$ and a covariate risk factor $\left(\sigma_{a}\right)$. In the theoretical discussion above, we distinguished between two types of household characteristics: those affecting households' preferences $\left(X_{p}\right)$ and those affecting household members' productivity $\left(X_{w}\right)$. However, in the reduced-form approach, it is difficult to clearly assign each $X$ either to $X_{p}$ or to $X_{w}$. For instance, the size of a household's landholdings, credit status, the number of working household members, and their educational attainment may affect both the household's preferences and household members' productivity. Therefore, we do not attempt to clearly assign each of these variables either to $X_{p}$ or to $X_{w}$ but treat these variables as those controlling for $X_{p}$ and $X_{w}$ jointly. In addition to the landholding size, we include a dummy for land ownership. Since the landholding size variable captures the marginal effect of having an additional acre of land, the landholding dummy captures the threshold effect for a landless household to become a landowner. We can safely attribute part of this threshold effect to risk tolerance.

Controlling for $X$, we test the prediction from Section 2 with respect to $\sigma_{a}$. As covariate 
risk factors, ideally, we should include not only $\sigma_{a}$, but also the full covariance matrix of shocks to off-farm wages and food prices. Due to data constraints, this is left for future research. As a proxy for the coefficient of variation of production shocks, the district-level coefficient of variation of annual rainfall ( $C V$ of rainfall) is employed. In addition, as another covariate risk factor, Rainfall shock is included to capture the ex post response of off-farm labor supply to production shocks. We would expect a negative coefficient on this variable if households increase their off-farm labor supply primarily as a result of a failure in rainfall. On the other hand, if households increase their off-farm labor supply in anticipation of rainfall shocks, then we would expect a positive coefficient on the $C V$ of rainfall variable.

As further control variables, we also include several village-level and district-level characteristics. Of these variables, a village-level irrigation indicator (Irrigation indicator) is intended to capture the impact of irrigation in reducing the village-level production risk. Because the extent to which the weather risk affects farm production differs according to the availability of irrigation facilities, we control for the effects of irrigation at the village and household levels. After controlling for these effects, we can expect $C V$ of rainfall to capture the precise impact of the covariate risk in agricultural production on labor supply.

\section{Estimation Results}

Using the dataset described above, we estimate the reduced-form determinants of off-farm labor supply. Since there are four dependent variables, all of which are censored at 0 and 100, we employ a multivariate two-limit tobit model. ${ }^{3}$ Estimation results are reported in Table 5 .

Among household characteristics, Land owned, Irrigation ratio, Agric. capital, and Livestock mostly have a positive effect on the on-farm labor supply $\left(\ell_{a}\right)$ and a negative effect on the off-farm supply $\left(\ell_{b}, \ell_{c}\right.$, and $\left.\ell_{d}\right)$. Since all of these variables raise the productivity of own farming, they mainly correspond to $X_{w}$ (productivity shifters) in the theoretical model. In addition, in the context of rural India, these variables are also indicators of wealth, which may reduce households' risk aversion (Kurosaki and Fafchamps, 2002). Thus, to some extent,

\footnotetext{
${ }^{3}$ We wrote a STATA program for the maximum likelihood estimator using the Geweke-Hajvassiliou-Keane (GHK) simulator to estimate the tobit model. The program is available on request.
} 
these variables also correspond to $X_{p}$ (preferences shifters) in the theoretical model.

Looking at education, we find that it significantly decreases the share of agricultural wage work. This reflects the lack of response of agricultural wages to human capital in South Asia (Kurosaki and Khan, 2006) and the stigma associated in rural India with working as an agricultural laborer. Once villagers are educated, they tend to be very reluctant to perform manual agricultural work for others. Turning to the demographic variables, we find that the larger the number of working-age males and of dependents in a household, the lower is the labor share allocated to own farming and the higher share devoted to off-farm wage work. On the other hand, the number of working-age females in a household does not have a significant effect in all four equations. This result reflects the fact that adult women in rural India typically perform domestic chores. Looking at the role of castes, we find that households belonging to backward or scheduled castes are more likely to send members to perform agricultural wage work. This result is consistent with Ito's (2007) finding of occupational segmentation or job discrimination against the backward castes using the same dataset.

Turning to the variable of interest in this paper, $C V$ of rainfall, we find that this has a significant negative impact on the on-farm labor supply $\left(\ell_{a}\right)$. Thus, the first theoretical prediction of (7) that the optimal on-farm labor supply is a decreasing function of farming risk is confirmed. This result implies that farm households facing riskier distributions of rainfall increase their off-farm labor supply. However, as shown in the table, the impact of weather risk varies widely across different types of off-farm work: while $C V$ of rainfall has a significant positive impact on $\ell_{c}$ (agricultural work paid in kind) and $\ell_{d}$ (non-agricultural wage work), the impact of weather risk on $\ell_{b}$ (agricultural work paid in cash) is negative and statistically insignificant. In addition, the magnitude of the increase is much larger for $\ell_{d}$ than for $\ell_{c}$. Thus, the second and third theoretical predictions of (7) that non-agricultural wage work absorbs a larger share of the displaced labor and the attractiveness of agricultural work increases when wages are paid in kind are confirmed. As predicted theoretically, agricultural households facing a greater weather risk tend to divert more labor to off-farm work, mainly in non-agriculture.

In contrast, while $C V$ of rainfall has expected signs in all four equations and mostly 
statistically significant, Rainfall shock does not: in the regressions for $\ell_{a}$ and $\ell_{d}$, the coefficient on Rainfall shock shows the opposite sign, contrary to our expectation, although it is not statistically significant. The coefficient on Rainfall shock in the regression for $\ell_{b}$ is positive and significant, implying that farmers supply more labor to this type of work when they receive more rain than usual. Our results are thus slightly different from Rose's result (2001) that bad weather shocks significantly increase the off-farm labor supply. Therefore, we conclude that off-farm labor in the study region serves more as an ex ante income diversifying measure than as an ex post measure.

To examine the robustness of our results, we try out various alternative specifications. Appendix II reports the detail. These additional results confirm that the share of the offfarm labor supply increases with weather risk, the increase is much larger in the case of non-agricultural work than in the case of agricultural wage work, and the increase is much larger in the case of agricultural wages paid in kind than in the cash wage case.

\section{A Simulation of the Impact of Weather Risk}

In this section, simulation exercises are conducted based on the estimation results reported in Table 5 in order to examine the economic significance of the effect of weather risk on offfarm labor supply. First, to compare our results with those of Rose (2001), the probability of wage labor market participation is simulated. Since the probability is not readily available from the multivariate tobit model adopted in this paper, we employ the procedure proposed by Cornick et al. (1994) and run Monte-Carlo simulations (see Appendix III for details).

Table 6 reports our simulation results. Despite the difference in methodology and data, our simulation results with respect to off-farm work (agricultural wage work paid in cash, agricultural wage work paid in kind, and non-agricultural wage work pooled; last column) are qualitatively similar to those obtained by Rose (2001). ${ }^{4}$ Our results indicate that, when the weather risk increases ( $C V$ of rainfall increases from its minimum to its maximum), the percentage of households participating in off-farm wage work increases from $49 \%$ to $77 \%$.

\footnotetext{
${ }^{4}$ Rose (2001) estimated a random effects probit model using a dummy variable for wage work participation as the dependent variable. Thus, her estimation results readily provide the figures for Table 6 without the need for Monte-Carlo simulations. In addition, she used three-year panel data of 2,115 households spanning 13 states of India in 1968/69 - 1970/71.
} 
Both figures are larger than those obtained by Rose (2001), but the direction of change is the same. However, our research approach allows us to go further and decompose this response into three types of wage work. Doing so indicates that agricultural work paid in cash decreases by 6 percentage points, while agricultural work paid in kind increases by 13 percentage points and non-agricultural work increases by as much as 38 percentage points. The impact of weather risk on off-farm labor participation is thus very different across sectors.

In the lower half of Table 6, we report simulation results of the expected changes in labor supply shares. The first two rows provide the response of $\ell_{j}$. These figures show that the labor share allocated to off-farm work increases with the increase in $C V$ of rainfall and the response of non-agricultural wage work is more substantial.

These results thus confirm that off-farm work in the non-agricultural sector plays an important role in diversifying farm production risk. It is implied, therefore, that empirical and theoretical studies on farmers' labor supply response to risk should distinguish between different types of off-farm work involved. This implication is also confirmed by the results of further specification tests reported in Table 7. We test the following null hypotheses: (1) all coefficients in the regressions for agricultural wage work $\left(\ell_{b}\right.$ and $\left.\ell_{c}\right)$ are equal and $(2)$ all coefficients in the regressions for all three wage work $\left(\ell_{b}, \ell_{c}\right.$, and $\left.\ell_{d}\right)$ are equal. The LR $\chi^{2}$ statistics show that both hypotheses are rejected at the $1 \%$ level, indicating that the sectoral difference is substantial.

\section{Conclusion}

This paper investigated the effects of weather risk on the off-farm labor supply of agricultural households in a developing country, distinguishing different types of off-farm labor markets: agriculture and non-agriculture on the one hand, and, wages paid in cash and wages paid in kind on the other. We developed a theoretical model of household optimization, which predicts that when farmers are faced with more production risk in their farm production, they find it more attractive to engage in non-agricultural work as a means of risk diversification, but the agricultural wage sector becomes more attractive when food security is an important issue for the farmers and agricultural wages are paid in kind. This prediction was confirmed by regression analyses using household data from rural areas of Bihar and Uttar Pradesh, 
India. Simulation results based on the regression estimates showed that the sectoral difference is substantial.

These results imply that risk avoidance inhibits gains from specialization and prevents farmers from achieving their output potential. Therefore, a crucial measure to reduce poverty in the study region would be to provide more efficient insurance or risk-reducing mechanisms. Such measures could take various forms: reducing variability in agricultural production and in food price by promoting risk-reducing technologies such as irrigation and/or food market integration, reducing the transmission of production shocks to income shocks through crop insurance schemes, improving credit opportunities to smooth consumption in the face of income shocks, etc. This study shows that labor markets potentially also play a role in reducing households' vulnerability to risk. If labor markets are used as an income diversifying measure, it is critically important to promote sectors whose wages are less correlated with farm production shocks. This is the main lesson of this paper.

Considering the considerable diversity of non-agricultural wage work, a possible extension of our research on off-farm labor as a means of diversifying risk would be to disaggregate non-agricultural wage labor opportunities. Since the regression model in this paper included only the variance term of the shock to own farming, incorporating a full set of correlation coefficients among the shocks to different sectors would be an interesting exercise. Since we did not attempt to clearly assign each of the household characteristics to either preference or productivity shifters, distinguishing the two more clearly would be another area for extension. These issues are left for further research using a dataset with additional variables. 


\section{Appendix I: Comparative Statics}

This appendix provides a comparative-static analysis of $\ell_{j}\left(\bar{L}, X_{p}, X_{w}, \Sigma\right), j=a, b, c, d$ (the optimal labor supply). In the comparative-static analysis, the term $v_{y}$ in the first order condition (5) is the key. Applying a Taylor approximation to $v_{y}$ and then totally differentiating Roy's identity, we obtain:

$$
v_{y} \approx \bar{v}_{y}\left\{1-\psi \frac{y-\bar{y}}{\bar{y}}+s(\psi-\eta) \frac{p-\bar{p}}{\bar{p}}\right\}
$$

where $\psi\left(\equiv-y v_{y y} / v_{y}\right)$ is the Arrow-Pratt measure of relative risk aversion, $s$ ( $\equiv p q / y$, where $q$ is the Marshallian demand for food) is the budget share of food, and $\eta$ ( $\equiv \partial \ln q / \partial \ln y$ ) is the income elasticity of food demand. $\psi, s$, and $\eta$ are all evaluated at the means of $y$ and $p$ so that they are treated as constant in the following exposition. Note that the assumption of $v_{y p}>0$ is equivalent to the assumption of $\psi>\eta$ in this approximation, which is likely to be satisfied for low-income households (Fafchamps, 1992).

The assumptions in Section 2 imply the following structure of $\Sigma$ (the covariance matrix of $\theta_{a}, \theta_{b}, \theta_{c}, \theta_{d}$, and $\left.\theta_{p}\right)$ :

$$
\Sigma=\left(\begin{array}{ccccc}
\sigma_{a}^{2} & \sigma_{a} \sigma_{b} \rho_{a b} & \sigma_{a} \sigma_{c} \rho_{a c} & 0 & \sigma_{a} \sigma_{p} \rho_{a} \\
\sigma_{a} \rho_{a b} \sigma_{b} & \sigma_{b}^{2} & \sigma_{b} \sigma_{c} \rho_{b c} & 0 & \sigma_{b} \sigma_{p} \rho_{b} \\
\sigma_{a} \sigma_{c} \rho_{a c} & \sigma_{b} \sigma_{c} \rho_{b c} & \sigma_{c}^{2} & 0 & \sigma_{c} \sigma_{p} \rho_{c} \\
0 & 0 & 0 & \sigma_{d}^{2} & 0 \\
\sigma_{a} \sigma_{p} \rho_{a} & \sigma_{b} \sigma_{p} \rho_{b} & \sigma_{c} \sigma_{p} \rho_{c} & 0 & \sigma_{p}^{2}
\end{array}\right)
$$

where $\sigma_{k}$ is the coefficient of variation of $\theta_{k}$ (note that the mean of $\theta_{k}$ is one), $\rho$ is the correlation coefficient, $0<\rho_{a b}<\rho_{a c}$, and $0<\rho_{b}<\rho_{c}$. We also assume that the magnitudes of $\sigma_{j}(j=a, b, c, d)$ are not very different. By inserting (8) and (9) into the first order condition (5), we obtain a system of equations, based on which we conduct the comparativestatic analysis. Since the system cannot be analyzed without additional restrictions, we investigate the simplest case for which it is possible to obtain analytical results and which is useful to understand the risk-aversion mechanism underlying the optimal labor choice. More concretely, we assume that $\partial f_{j} / \partial L=\partial f_{j} / \partial\left(\ell_{j} \bar{L}\right)=w$, i.e., labor returns are linear and their expected values are the same across sectors. With this specification, the household income becomes

$$
y=y_{0}+w \bar{L}\left\{\ell_{a} \theta_{a}+\ell_{b} \theta_{b}+\ell_{c} \theta_{c}+\left(1-\ell_{a}-\ell_{b}-\ell_{c}\right) \theta_{d}\right\}
$$


Inserting (8) into (5) and re-arranging, we obtain

$$
E\left[\bar{v}_{y}\left\{1-\psi \frac{y-\bar{y}}{\bar{y}}+s(\psi-\eta) \frac{p-\bar{p}}{\bar{p}}\right\}\left(\theta_{k}-\theta_{d}\right)\right]=0, \quad k=a, b, c .
$$

We then insert (9) and (10) into the expression above. After re-arranging, we obtain three equations:

$$
\begin{aligned}
& \ell_{a} \overbrace{\left(\sigma_{a}^{2}+\sigma_{d}^{2}\right)}^{=\Sigma_{a a}}+\ell_{b} \overbrace{\left(\sigma_{a} \sigma_{b} \rho_{a b}+\sigma_{d}^{2}\right)}^{=\Sigma_{a b}}+\ell_{c} \overbrace{\left(\sigma_{a} \sigma_{c} \rho_{a c}+\sigma_{d}^{2}\right)}^{=\Sigma_{a c}}-\sigma_{d}^{2}=\overbrace{\frac{\bar{y} s\left(1-\frac{\eta}{\psi}\right)}{w \bar{L}} \sigma_{a} \sigma_{p} \rho_{a},}^{s^{\prime \prime}} \\
& \ell_{a}\left(\sigma_{a} \sigma_{b} \rho_{a b}+\sigma_{d}^{2}\right)+\ell_{b} \overbrace{\left(\sigma_{b}^{2}+\sigma_{d}^{2}\right)}^{=\Sigma_{b b}}+\ell_{c} \overbrace{\left(\sigma_{b} \sigma_{c} \rho_{b c}+\sigma_{d}^{2}\right)}^{=\Sigma_{b c}}-\sigma_{d}^{2}=\frac{\bar{y} s}{w \bar{L}\left(1-\frac{\eta}{\psi}\right) \sigma_{b} \sigma_{p} \rho_{b},} \\
& \ell_{a}\left(\sigma_{a} \sigma_{c} \rho_{a c}+\sigma_{d}^{2}\right)+\ell_{b}\left(\sigma_{b} \sigma_{c} \rho_{b c}+\sigma_{d}^{2}\right)+\ell_{c} \overbrace{\left(\sigma_{c}^{2}+\sigma_{d}^{2}\right)}^{=\Sigma_{c c}}-\sigma_{d}^{2}=\frac{\bar{y} s}{w \bar{L}}\left(1-\frac{\eta}{\psi}\right) \sigma_{c} \sigma_{p} \rho_{c},
\end{aligned}
$$

where $\bar{y}=y_{0}+w \bar{L}$, which does not depend on the portfolio choice. For this reason, we treat it as a parameter and replace $\bar{y} s(1-\eta / \psi) /(w \bar{L})$ by $s^{\prime \prime}$. Therefore, the above system can be expressed as

$$
\left(\begin{array}{ccc}
\Sigma_{a a} & \Sigma_{a b} & \Sigma_{a c} \\
\Sigma_{a b} & \Sigma_{b b} & \Sigma_{b c} \\
\Sigma_{a c} & \Sigma_{b c} & \Sigma_{c c}
\end{array}\right)\left(\begin{array}{c}
\ell_{a} \\
\ell_{b} \\
\ell_{c}
\end{array}\right)=\left(\begin{array}{c}
\sigma_{d}^{2}+s^{\prime \prime} \sigma_{a} \sigma_{p} \rho_{a} \\
\sigma_{d}^{2}+s^{\prime \prime} \sigma_{b} \sigma_{p} \rho_{b} \\
\sigma_{d}^{2}+s^{\prime \prime} \sigma_{c} \sigma_{p} \rho_{c}
\end{array}\right)
$$

which can be solved to obtain a closed-form solution. Letting $D$ denote the determinant of the three-by-three matrix above, i.e., $D=\Sigma_{a a} \Sigma_{b b} \Sigma_{c c}+2 \Sigma_{a b} \Sigma_{b c} \Sigma_{a c}-\Sigma_{b c}^{2} \Sigma_{a a}-\Sigma_{a c}^{2} \Sigma_{b b}-\Sigma_{a b}^{2} \Sigma_{c c}$, we obtain the following closed-form solution:

$$
\begin{aligned}
& \ell_{a}=\frac{1}{D}\left[\sigma_{d}^{2}\{\overbrace{\left(\Sigma_{b b} \Sigma_{c c}-\Sigma_{b c}^{2}\right)+\left(\Sigma_{b c} \Sigma_{a c}-\Sigma_{a b} \Sigma_{c c}\right)+\left(\Sigma_{a b} \Sigma_{b c}-\Sigma_{b b} \Sigma_{a c}\right)}^{=R_{a}}\}\right. \\
& \left.+s^{\prime \prime} \sigma_{p}\{\underbrace{\sigma_{a} \rho_{a}\left(\Sigma_{b b} \Sigma_{c c}-\Sigma_{b c}^{2}\right)+\sigma_{b} \rho_{b}\left(\Sigma_{b c} \Sigma_{a c}-\Sigma_{a b} \Sigma_{c c}\right)+\sigma_{c} \rho_{c}\left(\Sigma_{a b} \Sigma_{b c}-\Sigma_{a c} \Sigma_{b b}\right)}_{=Q_{a}}\}\right], \\
& \ell_{b}=R_{b} \\
& +s^{\prime \prime} \sigma_{p}\{\underbrace{\frac{1}{D}\left[\sigma_{d}^{2}\{\overbrace{\left(\Sigma_{b c} \Sigma_{a c}-\Sigma_{a b} \Sigma_{c c}\right)+\left(\Sigma_{a a} \Sigma_{c c}-\Sigma_{a c}^{2}\right)+\left(\Sigma_{a b} \Sigma_{a c}-\Sigma_{a a} \Sigma_{b c}\right)}^{\left.\Sigma_{b c}-\Sigma_{a b} \Sigma_{c c}\right)+\sigma_{b} \rho_{b}\left(\Sigma_{a a} \Sigma_{c c}-\Sigma_{a c}^{2}\right)+\sigma_{c} \rho_{c}\left(\Sigma_{a b} \Sigma_{a c}-\Sigma_{a a} \Sigma_{b c}\right)}\}\right.}_{=Q_{b}}], \\
& \ell_{c}=R_{c} \\
& \frac{1}{D}\left[\sigma_{d}^{2}\{\overbrace{\left(\Sigma_{a b} \Sigma_{b c}-\Sigma_{a c} \Sigma_{b b}\right)+\left(\Sigma_{a c} \Sigma_{a b}-\Sigma_{a a} \Sigma_{b c}\right)+\left(\Sigma_{a a} \Sigma_{b b}-\Sigma_{a b}^{2}\right)}\}\right.
\end{aligned}
$$




$$
\begin{aligned}
& \left.+s^{\prime \prime} \sigma_{p}\{\underbrace{\sigma_{a} \rho_{a}\left(\Sigma_{a b} \Sigma_{b c}-\Sigma_{a c} \Sigma_{b b}\right)+\sigma_{b} \rho_{b}\left(\Sigma_{a b} \Sigma_{a c}-\Sigma_{a a} \Sigma_{b c}\right)+\sigma_{c} \rho_{c}\left(\Sigma_{a a} \Sigma_{b b}-\Sigma_{a b}^{2}\right)}_{=Q_{c}}\}\right] \\
& \ell_{d}=1-\sum_{i=a, b, c} \ell_{i}=1-\frac{1}{D}\left[\sigma_{d}^{2}\left(R_{a}+R_{b}+R_{c}\right)+s^{\prime \prime} \sigma_{p}\left(Q_{a}+Q_{b}+Q_{c}\right)\right]
\end{aligned}
$$

Now we investigate the comparative statics with respect to $\sigma_{a}$. First, a numerical example is shown in Figure A.1, where we set $s$ at $0.5, \bar{y} /(w \bar{L})$ at $1 / 0.8, \eta$ at $0.4, \psi$ at 2.0, $\rho_{a b}$ at $0.1, \rho_{a c}$ at $0.2, \rho_{b c}$ at $0.4, \rho_{a}$ at $-0.05, \rho_{b}$ at $0.1, \rho_{c}$ at $0.2, \sigma_{b}, \sigma_{c}, \sigma_{d}$ and $\sigma_{p}$ at 0.5 . The figure clearly supports the three predictions in (7): As self-employed farming becomes riskier, the own-farm labor supply $\left(\ell_{a}\right)$ declines, the labor supply share to agricultural wage work paid in kind $\left(\ell_{c}\right)$ increases more rapidly than that to agricultural wage work paid in cash $\left(\ell_{b}\right)$, and the labor supply share to non-agricultural wage work $\left(\ell_{d}\right)$ increases more rapidly than that to agricultural wage work paid in cash $\left(\ell_{b}\right)$.

\section{A.I.1 Impact of Farm Income Risk on the Farm Labor Share}

Since the shape of Figure A.1 is contingent on our specific choice of parameters, we examine the robustness of this shape in the followings. For simplicity's sake, in what follows, we assume that all the variances of risk factors are equal in order to focus on the effect of the covariances between risk factors.

Regarding the impact of farm income risk on the farm labor share, we take the partial derivative of (12) and obtain

$$
\frac{\partial \ell_{a}}{\partial \sigma_{a}}=\frac{1}{D}\left\{\sigma_{d}^{2} \frac{\partial R_{a}}{\partial \sigma_{a}}+s^{\prime \prime} \sigma_{p} \frac{\partial Q_{a}}{\partial \sigma_{a}}\right\}-\frac{\ell_{a}}{D} \frac{\partial D}{\partial \sigma_{a}} .
$$

In general, the sign of the above expression is indeterminate. However, with some additional assumptions, we can show that $\partial \ell_{a} / \partial \sigma_{a}<0$. First,

$$
\begin{aligned}
\frac{\partial R_{a}}{\partial \sigma_{a}} & =\Sigma_{b c} \sigma_{c} \rho_{a c}-\Sigma_{c c} \sigma_{b} \rho_{a b}+\Sigma_{b c} \sigma_{b} \rho_{a b}-\Sigma_{b b} \sigma_{c} \rho_{a c} \\
& =\sigma_{b} \rho_{a b}\left(\Sigma_{b c}-\Sigma_{c c}\right)+\sigma_{c} \rho_{a c}\left(\Sigma_{b c}-\Sigma_{b b}\right) \underbrace{<0 .}_{\text {since } \rho_{b c}<1 \& \sigma_{b} \approx \sigma_{c}}
\end{aligned}
$$

Second,

$\frac{\partial Q_{a}}{\partial \sigma_{a}} \quad=\quad \rho_{a}\left(\Sigma_{b b} \Sigma_{c c}-\Sigma_{b c}^{2}\right)+\sigma_{b} \rho_{b}\left(\sigma_{c} \rho_{a c} \Sigma_{b c}-\sigma_{b} \rho_{a b} \Sigma_{c c}\right)+\sigma_{c} \rho_{c}\left(\sigma_{b} \rho_{a b} \Sigma_{b c}-\sigma_{c} \rho_{a c} \Sigma_{b b}\right)$ 


$$
\begin{array}{cl}
\underbrace{\approx}_{\text {since } \sigma_{b} \approx \sigma_{c}} & \rho_{a}\left(\Sigma_{b b}^{2}-\Sigma_{b c}^{2}\right)+\sigma_{b}^{2}\left\{\rho_{a c}\left(\rho_{b} \Sigma_{b c}-\rho_{c} \Sigma_{b b}\right)+\rho_{a b}\left(\rho_{c} \Sigma_{b c}-\rho_{b} \Sigma_{b b}\right)\right\} \\
\underbrace{<}_{\text {since } \rho_{b c}<1} & \rho_{a}\left(\Sigma_{b b}^{2}-\Sigma_{b c}^{2}\right)+\sigma_{b}^{2} \Sigma_{b b}\left\{\rho_{a c}\left(\rho_{b}-\rho_{c}\right)+\rho_{a b}\left(\rho_{c}-\rho_{b}\right)\right\} \\
= & \rho_{a}\left(\Sigma_{b b}^{2}-\Sigma_{b c}^{2}\right)+\sigma_{b}^{2} \Sigma_{b b}\left\{\left(\rho_{a c}-\rho_{a b}\right)\left(\rho_{b}-\rho_{c}\right)\right\} \\
\underbrace{<}_{\text {since } \rho_{a c}>\rho_{a b} \& \rho_{c}>\rho_{b}} & \rho_{a}\left(\Sigma_{b b}^{2}-\Sigma_{b c}^{2}\right) \underbrace{<}_{\text {if } \rho_{a}<0} 0 .
\end{array}
$$

Note that $\partial Q_{a} / \partial \sigma_{a}$ is more likely to be negative when $\rho_{a}<0$, i.e., when farmers enjoy a higher gross income from crops, the food price tends to be lower, which seems to fit the situations in rural India. The assumption of the negative correlation between farm income and food price, $\rho_{a}<0$, is not necessary to show our predictions in (7), however. We can obtain a similar conclusion if $\rho_{a}$ is positive but sufficiently small. And third,

$$
\begin{array}{rl}
\frac{\partial D}{\partial \sigma_{a}} & =2 \sigma_{a} \Sigma_{b b} \Sigma_{c c}+2 \sigma_{b} \rho_{a b} \Sigma_{a c} \Sigma_{b c}+2 \sigma_{c} \rho_{a c} \Sigma_{a b} \Sigma_{b c}-2 \sigma_{a} \Sigma_{b c}^{2}-2 \sigma_{c} \rho_{a c} \Sigma_{a c} \Sigma_{b b}-2 \sigma_{b} \rho_{a b} \Sigma_{a b} \Sigma_{c c} \\
& =2 \sigma_{a} \Sigma_{b b} \Sigma_{c c}\left(1-\frac{\Sigma_{b c}^{2}}{\Sigma_{b b} \Sigma_{c c}}\right)-2 \sigma_{b} \rho_{a b} \Sigma_{a b} \Sigma_{c c}\left(1-\frac{\Sigma_{a c} \Sigma_{b c}}{\Sigma_{a b} \Sigma_{c c}}\right)-2 \sigma_{c} \rho_{a c} \Sigma_{a c} \Sigma_{b b}\left(1-\frac{\Sigma_{a b} \Sigma_{b c}}{\Sigma_{a c} \Sigma_{b b}}\right) \\
\text { since } \underbrace{}_{a} \approx \sigma_{b} \approx \sigma_{c} & 2 \sigma_{b} \Sigma_{b b}^{2}\left(1-\frac{\Sigma_{b c}^{2}}{\Sigma_{b b}^{2}}\right)-2 \sigma_{b} \rho_{a b} \Sigma_{a b} \Sigma_{b b}\left(1-\frac{\Sigma_{a c} \Sigma_{b c}}{\Sigma_{a b} \Sigma_{b b}}\right)-2 \sigma_{b} \rho_{a c} \Sigma_{a c} \Sigma_{b b}\left(1-\frac{\Sigma_{a b} \Sigma_{b c}}{\Sigma_{a c} \Sigma_{b b}}\right) \\
\underbrace{\geq}_{\text {since } \rho_{a c}>\rho_{a b}} 2 \sigma_{b} \Sigma_{b b}\left\{\Sigma_{b b}\left(1-\frac{\Sigma_{b c}^{2}}{\Sigma_{b b}^{2}}\right)-\left(\rho_{a b} \Sigma_{a b}+\rho_{a c} \Sigma_{a c}\right)\left(1-\frac{\Sigma_{a b} \Sigma_{b c}}{\Sigma_{a c} \Sigma_{b b}}\right)\right\} \\
\underbrace{\geq}_{\text {if } \rho_{a c}, \rho_{b c} \leq \frac{1}{2} \& \rho_{a c} \rho_{b c} \leq 2 \rho_{a b}} 2 \sigma_{b} \Sigma_{b b}\left(\Sigma_{b b}-\rho_{a b} \Sigma_{a b}-\rho_{a c} \Sigma_{a c}\right)\left(1-\frac{\Sigma_{b c}^{2}}{\Sigma_{b b}^{2}}\right) \underbrace{\geq}_{\text {if } \rho_{a b}, \rho_{a c}<\frac{1}{2}} 0 .
\end{array}
$$

Note that $\partial D / \partial \sigma_{a}$ is more likely to be positive when $\sigma_{a}>\sigma_{b}\left(\sigma_{c}\right)$, which seems to fit the situations in rural India, but as shown above, even in the case of $\sigma_{a} \approx \sigma_{b}\left(\sigma_{c}\right)$, it becomes positive if the correlation coefficients are sufficiently small to satisfy $\rho_{a c}<1 / 2, \rho_{b c} \leq 1 / 2$ and $\rho_{a c} \rho_{b c} / 2 \leq \rho_{a b}<1 / 2$. Thus, we obtain the relation $\partial \ell_{a} / \partial \sigma_{a}<0$, which predicts that the own-farm labor supply declines as production becomes riskier. A corollary of this prediction is $\partial\left(\ell_{b}+\ell_{c}+\ell_{d}\right) / \partial \sigma_{a}>0$, which predicts that the sum of the off-farm labor supply shares increases as self-employed farming becomes riskier.

\section{A.I.2 Impact of Farm Income Risk on Labor Supply to Off-Farm Sectors}

Now we investigate which among the three off-farm sectors expands most rapidly when selfemployed farming becomes riskier. First, we examine the choice between agricultural wage 
work paid in cash and agricultural wage work paid in kind. Taking the partial derivatives of (13) and (14), we obtain

$$
\frac{\partial \ell_{c}}{\partial \sigma_{a}}-\frac{\partial \ell_{b}}{\partial \sigma_{a}}=\frac{1}{D}\left\{\sigma_{d}^{2}\left(\frac{\partial R_{c}}{\partial \sigma_{a}}-\frac{\partial R_{b}}{\partial \sigma_{a}}\right)+s^{\prime \prime} \sigma_{p}\left(\frac{\partial Q_{c}}{\partial \sigma_{a}}-\frac{\partial Q_{b}}{\partial \sigma_{a}}\right)\right\}-\frac{\left(\ell_{c}-\ell_{b}\right)}{D} \frac{\partial D}{\partial \sigma_{a}} .
$$

The sign of the above expression depends on the signs of $\partial\left(R_{c}-R_{b}\right) / \partial \sigma_{a}, \partial\left(Q_{c}-Q_{b}\right) / \partial \sigma_{a}$, $\ell_{c}-\ell_{b}$, and $\partial D / \partial \sigma_{a}$. As shown for the case of $\partial \ell_{a} / \partial \sigma_{a}$, it is likely that $\partial D / \partial \sigma_{a}>0$. Furthermore,

$$
\begin{aligned}
\frac{\partial Q_{c}}{\partial \sigma_{a}}-\frac{\partial Q_{b}}{\partial \sigma_{a}}= & -\rho_{a}\left(\Sigma_{a c} \Sigma_{b b}-\Sigma_{a b} \Sigma_{c c}\right)+\left(\Sigma_{b c} \Sigma_{a c}-\Sigma_{a b} \Sigma_{b c}\right) \\
& \left.+\left(\sigma_{a} \rho_{a b} \sigma_{b} \Sigma_{c c}-\sigma_{a} \rho_{a b} \sigma_{b} \Sigma_{b c}\right)+\left(\sigma_{a} \rho_{a c} \sigma_{c} \Sigma_{b b}-\sigma_{a} \rho_{a c} \sigma_{c} \Sigma_{b c}\right)\right\} \\
& +\rho_{b} \sigma_{b}\left\{2\left(-\sigma_{a} \Sigma_{c c}+\sigma_{c} \rho_{a c} \Sigma_{a c}\right)\right. \\
& \left.+2 \sigma_{a} \sigma_{b} \sigma_{c}\left(-\rho_{b c}+\rho_{a b} \rho_{a c}\right)+\sigma_{d}^{2}\left(-2 \sigma_{a}+\sigma_{b} \rho_{a b}+\sigma_{c} \rho_{a c}\right)\right\} \\
& +\rho_{c} \sigma_{c}\left\{2\left(\sigma_{a} \Sigma_{b b}-\sigma_{b} \rho_{a b} \Sigma_{a b}\right)\right. \\
& \left.+2 \sigma_{a} \sigma_{b} \sigma_{c}\left(\rho_{b c}-\rho_{a b} \rho_{a c}\right)+\sigma_{d}^{2}\left(2 \sigma_{a}-\sigma_{b} \rho_{a b}-\sigma_{c} \rho_{a c}\right)\right\} \\
\underbrace{}_{\text {since } \rho_{a b}<} & -\rho_{a c}\{\underbrace{\left(\Sigma_{a c} \Sigma_{b b}-\Sigma_{a b} \Sigma_{c c}\right)}_{>0}+\underbrace{\left(\Sigma_{b c} \Sigma_{a c}-\Sigma_{a b} \Sigma_{b c}\right)}_{>0} \\
& +\underbrace{\left(\sigma_{a} \rho_{a b} \sigma_{b} \Sigma_{c c}-\sigma_{a} \rho_{a b} \sigma_{b} \Sigma_{b c}\right)}_{>0}+\underbrace{\left(\sigma_{a} \rho_{a c} \sigma_{c} \Sigma_{b b}-\sigma_{a} \rho_{a c} \sigma_{c} \Sigma_{b c}\right)}_{>0}\} \\
& +\underbrace{\left(\rho_{c} \sigma_{c}-\rho_{b} \sigma_{b}\right)}_{>0}\{2 \underbrace{\left(\sigma_{a} \Sigma_{b b}-\sigma_{b} \rho_{a b} \Sigma_{a b}\right)}_{>0} \\
& +2 \sigma_{a} \sigma_{b} \sigma_{c}\left(\rho_{b c}-\rho_{a b} \rho_{a c}\right)+\sigma_{d}^{2} \underbrace{\left(2 \sigma_{a}-\sigma_{b} \rho_{a b}-\sigma_{c} \rho_{a c}\right)}_{>0}\} .
\end{aligned}
$$

Therefore, if we additionally assume that $\rho_{a}<0$ and the correlation between cash and inkind wages in agricultural labor market is moderately high so that $\rho_{b c}>\rho_{a b} \rho_{a c}$, which seems plausible in the context of rural India, we can assign the sign of $\partial\left(Q_{c}-Q_{b}\right) / \partial \sigma_{a}$ as positive. Thus, when $\ell_{c} \leq \ell_{b}$ and $\partial\left(R_{c}-R_{b}\right) / \partial \sigma_{a} \geq 0$, we obtain the relation $\partial\left(\ell_{c}-\ell_{b}\right) / \partial \sigma_{a}>0$, which predicts that the labor supply share to wage work paid in kind increases more rapidly than that to wage work paid in cash, as self-employed farming becomes riskier. When $\ell_{c}>\ell_{b}$ or $\partial\left(R_{c}-R_{b}\right) / \partial \sigma_{a}<0$, the sign of $\partial\left(\ell_{c}-\ell_{b}\right) / \partial \sigma_{a}$ is indeterminate, although it is more likely to be positive when $s^{\prime \prime}$ is large, i.e., the household's food budget share is high, the household is highly risk averse, and the household's food demand is inelastic. In the numerical simulation, the positive effect of $\partial\left(Q_{c}-Q_{b}\right) / \partial \sigma_{a}$ is dominant, although $\left(\ell_{c}-\ell_{b}\right)$ is positive and $\partial\left(R_{c}-R_{b}\right) / \partial \sigma_{a}$ is negative. 
Finally, we investigate the choice between agricultural and non-agricultural wage work. From (13) and (15), we obtain

$$
\begin{aligned}
\frac{\partial \ell_{d}}{\partial \sigma_{a}}-\frac{\partial \ell_{b}}{\partial \sigma_{a}} & =\frac{1}{D}\left\{\sigma_{d}^{2}\left(-\frac{\partial R_{a}}{\partial \sigma_{a}}-2 \frac{\partial R_{b}}{\partial \sigma_{a}}-\frac{\partial R_{c}}{\partial \sigma_{a}}\right)+s^{\prime \prime} \sigma_{p}\left(-\frac{\partial Q_{a}}{\partial \sigma_{a}}-2 \frac{\partial Q_{b}}{\partial \sigma_{a}}-\frac{\partial Q_{c}}{\partial \sigma_{a}}\right)\right\} \\
& +\frac{\ell_{a}+2 \ell_{b}+\ell_{c}}{D} \frac{\partial D}{\partial \sigma_{a}} .
\end{aligned}
$$

We already showed that the combination of $\partial R_{a} / \partial \sigma_{a}<0, \partial Q_{a} / \partial \sigma_{a}<0$, and $\partial D / \partial \sigma_{a}>0$ is likely. Therefore, when the absolute values of $\partial R_{b} / \partial \sigma_{a} \approx \partial R_{c} / \partial \sigma_{a}$ are small and the absolute values of $\partial Q_{b} / \partial \sigma_{a}$ and $\partial Q_{c} / \partial \sigma_{a}$ are small, we expect the relation $\partial\left(\ell_{d}-\ell_{b}\right) / \partial \sigma_{a}>0$, which predicts that the labor supply share to non-agricultural wage work increases more rapidly than that to agricultural wage work, as self-employed farming becomes riskier. This relation also holds in cases where $\sigma_{d}^{2}$ and $s^{\prime \prime}$ are sufficiently small. Regarding Figure A.1, we observe the relation $\partial\left(\ell_{d}-\ell_{b}\right) / \partial \sigma_{a}>0$ because the absolute values of $\partial R_{b} / \partial \sigma_{a}, \partial R_{c} / \partial \sigma_{a}$, $\partial Q_{b} / \partial \sigma_{a}$, and $\partial Q_{c} / \partial \sigma_{a}$ are small. Note that in typical situations in developing countries, $s^{\prime \prime}$ is not very small, because the household's food budget share is high, the household is highly risk averse, and the household's food demand is inelastic.

\section{Appendix II: Robustness Checks}

In this appendix, we conduct several robustness checks of our main result shown in Table 5. Table A-1 shows the estimation results under alternative specifications: with village and district characteristics excluded (column 1), with district characteristics excluded (column 2), and with no adjustment for the possible correlation between errors (column 4). Column 3 of the table repeats our main result reported in Table 5 for the comparison purpose.

Comparing columns 1,2 , and 3 , we find that the signs and the statistical significance of the estimated coefficients on risk factors are essentially unchanged, but the absolute values of the coefficients become larger as we include more village- or district-level control variables. This seems to suggest that the impacts of risk factors are likely to be underestimated when heterogeneity across villages or districts is ignored. On the other hand, the ignorance of the correlation between errors (column 4) does not change the magnitudes of the coefficients very much. 
While the likelihood ratio (LR) $\chi^{2}$ statistics in the last row of the table indicate the rejection of all three alternative specifications, this does not mean that there is no suspicion of omitted variable bias in our main result. For instance, it is possible that the districts are different in terms of labor market conditions and this heterogeneity is not controlled adequately in our main result. In order to show that this possibility is not high, we further estimate the labor supply model with district dummies included, instead of district characteristics and rainfall variables. If the coefficients on household-level and village-level variables change substantially from our main result, a suspicion of omitted variable bias could be raised. By using a Wald test, we test the null hypothesis that the coefficient estimates in our main result and those in the regression with district dummies are equal. The $\chi^{2}$ statistics are $7.71,7.34,13.99$, and 3.74 for each equation, indicating that the difference in the estimates is not statistically significant. ${ }^{5}$ Thus, we expect the omitted variable bias to be rather small, even if unobserved heterogeneity exists across districts.

\section{Appendix III: Simulation Procedure}

In this appendix, we explain the simulation procedure used to obtain the results reported in Table 6. We follow the procedure outlined by Cornick et al. (1994).

First, we simulate $T$ runs of a $(4 \times 1)$ vector of error terms $u$ using Cholesky factorization of the covariance matrix $\widehat{\Sigma}$ estimated by the multivariate tobit model:

$$
\begin{aligned}
\widehat{u}_{t} & =L S_{t}, \\
E\left[\widehat{u}_{t}\right] & =L E\left[S_{t}\right]=0, \\
V\left[\widehat{u}_{t}\right] & =L V\left[S_{t}\right] L^{\prime}=L I L^{\prime}=\widehat{\Sigma},
\end{aligned}
$$

where $S_{t}$ is a $(4 \times 1)$ vector of random numbers obtained from a univariate standard normal distribution in the $t$-th trial, and $L$ is a lower triangular matrix defined in the last equation of (19). Then for each run, we assign each observation (household) to a pattern of labor allocation shown in Table 1, and obtain the following two pattern vectors, both of which are

\footnotetext{
${ }^{5}$ The degree of freedom is 22 (there are 15 household-level variables and 7 village-level variables). The estimation results with district dummies are available on request.
} 
$4 \times 1$ (U: uncensored and C: censored at the upper limit):

$$
\begin{aligned}
& U_{t}=\left(\begin{array}{c}
1\left[100-X \widehat{\beta}_{a}>\widehat{u}_{a, t}>-X \widehat{\beta}_{a}\right] \\
\vdots \\
1\left[100-X \widehat{\beta}_{d}>\widehat{u}_{d, t}>-X \widehat{\beta}_{d}\right]
\end{array}\right)=\left(\begin{array}{c}
U_{a, t} \\
\vdots \\
U_{d, t}
\end{array}\right), \\
& C_{t}=\left(\begin{array}{c}
1\left[\widehat{u}_{a, t} \geq 100-X \widehat{\beta}_{a}\right] \\
\vdots \\
1\left[\widehat{u}_{d, t} \geq 100-X \widehat{\beta}_{d}\right]
\end{array}\right)=\left(\begin{array}{c}
C_{a, t} \\
\vdots \\
C_{d, t}
\end{array}\right),
\end{aligned}
$$

where $1[\cdot]$ is an indicator function that takes unity if the condition in the bracket is true and zero otherwise, $X$ is the vector of explanatory variables, and $\widehat{\beta}_{k}$ is the vector of estimated coefficients in the equation $k(k=a$ : self-employment in agriculture, $b$ : wage work in agriculture paid in cash, $c$ : wage work in agriculture paid in kind, $d$ : wage work in nonagriculture).

Using these pattern vectors and letting $\tilde{\ell}_{k}$ denote the latent and uncensored variable for the labor share, we approximate the probabilities that a household allocates labor to each type of work by the followings.

$$
\left(\begin{array}{c}
\widehat{\operatorname{Pr}}\left(\ell_{a}>0\right) \\
\vdots \\
\widehat{\operatorname{Pr}}\left(\ell_{d}>0\right)
\end{array}\right)=\left(\begin{array}{c}
\widehat{\operatorname{Pr}}\left(100>\tilde{\ell}_{a}>0\right)+\widehat{\operatorname{Pr}}\left(\tilde{\ell}_{a} \geq 100\right) \\
\vdots \\
\widehat{\operatorname{Pr}}\left(100>\tilde{\ell}_{d}>0\right)+\widehat{\operatorname{Pr}}\left(\tilde{\ell}_{d} \geq 100\right)
\end{array}\right)=\frac{\sum_{t=1}^{T} U_{t}+\sum_{t=1}^{T} C_{t}}{T} .
$$

In addition, the expected labor supply share is given by

$$
\begin{aligned}
E\left[\ell_{k}\right] & =0 \times \operatorname{Pr}\left(\tilde{\ell}_{k} \leq 0\right)+E\left[\tilde{\ell}_{k} \mid 100>\tilde{\ell}_{k}>0\right] \times \operatorname{Pr}\left(100>\tilde{\ell}_{k}>0\right)+100 \times \operatorname{Pr}\left(\tilde{\ell}_{k} \geq 100\right) \\
& =\left\{X \beta_{k}+E\left[u_{k} \mid 100>\tilde{\ell}_{k}>0\right]\right\} \times \operatorname{Pr}\left(100>\tilde{\ell}_{k}>0\right)+100 \times \operatorname{Pr}\left(\tilde{\ell}_{k} \geq 100\right), \quad k=a, b, c, d
\end{aligned}
$$

Therefore, $E\left[\ell_{k}\right]$ can be estimated by using the predicted probabilities, $\widehat{\operatorname{Pr}}\left(100>\tilde{\ell}_{k}>0\right)$ and $\widehat{\operatorname{Pr}}\left(\tilde{\ell}_{k} \geq 100\right)$ in equation (20), and the expected value of error terms conditional on being uncensored defined by

$$
\widehat{E}\left[u_{k} \mid 100>\tilde{\ell}_{k}>0\right]=\frac{\sum_{t=1}^{T} \widehat{u}_{k} U_{k, t}}{\sum_{t=1}^{T} U_{k, t}} .
$$

Note that the reported figures in Table 6 are the mean predicted values when $T$ is set to $50 .^{6}$

\footnotetext{
${ }^{6}$ The simulation results are not sensitive to marginal changes in $T$ around 50 .
} 


\section{References}

Cameron, L. A. and C. Worswick, 2003. "The Labor Market as a Smoothing Device: Labor Supply Responses to Crop Loss." Review of Development Economics 7(2): 327-341.

Cornick, J., T. L. Cox, and B. W. Gould, 1994. "Fluid Milk Purchases: A Multivariate Tobit Analysis." American Journal of Agricultural Economics 76(1): 74-82.

Dercon, S. (ed.), 2005. Insurance Against Poverty. Oxford: Oxford University Press.

Fafchamps, M., 1992. "Cash Crop Production, Food Price Volatility, and Rural Market Integration in the Third World." American Journal of Agricultural Economics 74(1): 90-99.

—, 2003. Rural Poverty, Risk and Development. Cheltenham, UK: Edward Elger.

GOI (Government of India), 1991-2000. Agricultural Wages in India, 1990/1991 to 1998/1999. New Delhi: The Ministry of Food and Agriculture, GOI.

—, 2001. District-wise Area, Production and Yield of Rice Across the States During 19902000. New Delhi: The Directorate of Rice Development, GOI.

Johnson, M., K. Matsuura, C. Willmott, and P. Zimmermann, 2003. Tropical Land-Surface Precipitation: Gridded Monthly and Annual Time Series (1950-1999).

Ito, T., 2007. "Caste Discrimination and Transaction Costs in the Labor Market: Evidence from Rural North India", Hi-Stat Discussion Paper Series, No. 200. Institute of Economic Research, Hitotsubashi University, Tokyo (available at http://hi-stat.ier.hitu.ac.jp/research/discussion/2006/200.html).

Kimball, M.S., 1990. "Precautionary Saving in the Small and in the Large." Econometrica 58(1): 53-73..

Kochar, A., 1997a. "An Empirical Investigation of Rationing Constraints in Rural Credit Markets in India." Journal of Development Economics 53(2): 339-371.

— , 1997b. "Does Lack of Access to Formal Credit Constrain Agricultural Production? Evidence from the Land Tenancy Market in Rural India." American Journal of Agricultural Economics 79(3): 754-763.

— , 1999. "Smoothing Consumption by Smoothing Income: Hours of Work Response to Idiosyncratic Agricultural Shocks in Rural India." Review of Economic and Statistics 81(1): $50-61$. 
Kurosaki, T., 1995. "Risk and Insurance in a Household Economy: Role of Livestock in Mixed Farming in Pakistan." Developing Economies 33(4): 464-485.

— , 2006. "Labor Contracts, Incentives, and Food Security in Rural Myanmar." Hi-Stat Discussion Paper Series, No. 134. Institute of Economic Research, Hitotsubashi University, Tokyo (available at http://hi-stat.ier.hit-u.ac.jp/research/discussion/2005/134.html).

Kurosaki, T. and M. Fafchamps, 2002. "Insurance Market Efficiency and Crop Choices in Pakistan." Journal of Development Economics 67(2): 419-453.

Kurosaki, T. and H. Khan, 2006. "Human Capital, Productivity, and Stratification in Rural Pakistan." Review of Development Economics 10(1): 116-134.

Lanjouw, P. and A. Shariff, 2004. "Rural Non-Farm Employment in India : Access, Income and Poverty Impact." Economic and Political Weekly, Oct. 2: 4429-4446.

NSSO (National Sample Surveys Organisation), 2000. Employment and Unemployment in India 1999/2000, New Delhi: NSSO.

Rose, E., 2001. "Ex Ante and Ex Post Labor Supply Response to Risk in a Low-Income Area." Journal of Development Economics 64(2): 371-388.

Singh, I., L. Squire, and J. Strauss, 1986. Agricultural Household Models: Extensions, Applications, and Policy, Baltimore: Johns Hopkins University Press.

Townsend, R.M., 1994. "Risk and Insurance in Village India." Econometrica 62(3): 539591.

Walker, T.S. and J.G. Ryan, 1990. Village and Household Economies in India's Semi-arid Tropics. Baltimore: Johns Hopkins University Press. 
Table 1: Labor Allocation Patterns in Bihar and Uttar Pradesh, India

\begin{tabular}{|c|c|c|c|c|c|}
\hline Pattern & No. & Freq. & Pattern & No. & Freq. \\
\hline \multicolumn{3}{|l|}{ (A) Self-employment only } & \multicolumn{3}{|c|}{ (D) Self-emp. non-agric. and wage work } \\
\hline (a) only & 353 & $21.1 \%$ & (b) and (e) & 1 & $0.1 \%$ \\
\hline (e) only & 16 & $1.0 \%$ & (c) and (e) & 5 & $0.3 \%$ \\
\hline (a) and (e) & 322 & $19.3 \%$ & (d) and (e) & 12 & $0.7 \%$ \\
\hline \multirow[t]{2}{*}{ Sub-total of (A) } & 691 & $41.4 \%$ & (b), (c), and (e) & 7 & $0.4 \%$ \\
\hline & & & (b), (d), and (e) & 3 & $0.2 \%$ \\
\hline (B) Wage work only & & & $(\mathrm{c}),(\mathrm{d})$, and $(\mathrm{e})$ & 6 & $0.4 \%$ \\
\hline (b) only & 7 & $0.4 \%$ & (b), (c), (d), and (e) & 4 & $0.2 \%$ \\
\hline (c) only & 10 & $0.6 \%$ & Sub-total of (D) & 38 & $2.3 \%$ \\
\hline (d) only & 38 & $2.3 \%$ & & & \\
\hline (b) and (c) & 12 & $0.7 \%$ & (E) Other & & \\
\hline (b) and (d) & 7 & $0.4 \%$ & (a), (b), and (e) & 7 & $0.4 \%$ \\
\hline (c) and (d) & 12 & $0.7 \%$ & (a), (c), and (e) & 16 & $1.0 \%$ \\
\hline$(\mathrm{b}),(\mathrm{c})$, and $(\mathrm{d})$ & 10 & $0.6 \%$ & (a), (d), and (e) & 123 & $7.4 \%$ \\
\hline \multirow[t]{2}{*}{ Sub-total of (B) } & 96 & $5.7 \%$ & (a), (b), (c), and (e) & 17 & $1.0 \%$ \\
\hline & & & $(\mathrm{a}),(\mathrm{b}),(\mathrm{d})$, and $(\mathrm{e})$ & 19 & $1.1 \%$ \\
\hline \multicolumn{3}{|c|}{ (C) Self-emp. agric. and wage work } & $(\mathrm{a}),(\mathrm{c}),(\mathrm{d})$, and (e) & 19 & $1.1 \%$ \\
\hline (a) and (b) & 31 & $1.9 \%$ & (a), (b), (c), (d), and (e) & 36 & $2.2 \%$ \\
\hline (a) and (c) & 15 & $0.9 \%$ & Sub-total of $(E)$ & 237 & $14.2 \%$ \\
\hline (a) and (d) & 332 & $19.9 \%$ & & & \\
\hline (a), (b), and (c) & 45 & $2.7 \%$ & Including (a) & 1520 & $91.0 \%$ \\
\hline (a), (b), and (d) & 30 & $1.8 \%$ & Including (b) or (c) & 474 & $28.4 \%$ \\
\hline (a), (c), and (d) & 52 & $3.1 \%$ & Including (d) & 806 & $48.3 \%$ \\
\hline (a), (b), (c), and (d) & 103 & $6.2 \%$ & Including (b), (c), or (d) & 979 & $58.6 \%$ \\
\hline Sub-total of $(\mathrm{C})$ & 608 & $36.4 \%$ & Grand total (A-E) & 1670 & $100.0 \%$ \\
\hline
\end{tabular}

Notes:(a) = Self-employment in agriculture; $(\mathrm{b})=$ Wage work in agriculture paid in cash; $(\mathrm{c})=$ Wage work in agriculture paid in kind; (d) = Wage work in non-agriculture; (e) = Self-employment in non-agriculture. 
Table 2: Household Characteristics by Labor Allocation Pattern

\begin{tabular}{|c|c|c|c|c|}
\hline & $\begin{array}{l}\text { No. of } \\
\text { obs. }\end{array}$ & $\begin{array}{c}\text { Lower } \\
\text { caste }^{(1)} \\
(\%)\end{array}$ & $\begin{array}{c}\text { Annual labor } \\
\text { supply }^{(2)} \\
\text { (hours) }\end{array}$ & $\begin{array}{c}\text { No. of } \\
\text { working } \\
\text { members }{ }^{(2)}\end{array}$ \\
\hline Total & 1670 & 81.14 & 3240.67 & 2.43 \\
\hline \multicolumn{5}{|l|}{ Labor allocation pattern: } \\
\hline Self-employment only & 691 & 74.24 & 2623.76 & 2.09 \\
\hline Including (b) or (c) & 474 & 96.84 & 3503.16 & 2.71 \\
\hline \multirow[t]{2}{*}{ Including (d) } & 806 & 83.62 & 3851.89 & 2.74 \\
\hline & & $\begin{array}{c}\text { No. of } \\
\text { working age } \\
\text { members }\end{array}$ & $\begin{array}{l}\text { No. of non- } \\
\text { working age } \\
\text { members }{ }^{(2)}\end{array}$ & $\begin{array}{l}\text { Size of farmland } \\
\text { owned by the } \\
\text { household } \\
\text { (acres) }\end{array}$ \\
\hline Total & & 3.60 & 3.06 & 2.71 \\
\hline \multicolumn{5}{|l|}{ Labor allocation pattern: } \\
\hline Self-employment only & & 3.48 & 2.97 & 3.74 \\
\hline Including (b) or (c) & & 3.15 & 3.05 & 1.23 \\
\hline Including (d) & & 3.88 & 3.21 & 2.17 \\
\hline
\end{tabular}

Note: (1) The share of households belonging neither to middle or upper Hindu caste.

(2) Reported figures are the averages for all households. 'Annual labor supply' is the sum of hours working on own farm, hours supplied to wage work outside, and hours working on own non-farm enterprise. Working age members are defined as those aged between 15 and 60 . 
Table 3: The Effects of Rainfall on Rice Production and Market Wages

\begin{tabular}{lrlrlrl}
\hline & \multicolumn{2}{c}{ Rice production } & \multicolumn{2}{c}{ Agric. wages } & \multicolumn{2}{c}{ Non-agric. wages } \\
\hline Land under paddy & 60.308 & $(9.34)^{* * *}$ & \multicolumn{2}{c}{-} & - \\
Rainfall & 11.278 & $(3.38)^{* * *}$ & 2.45 & $(1.83)^{*}$ & 0.42 & $(0.24)$ \\
Intercept & 172.408 & $(70.75)^{* * *}$ & 18.45 & $(8.57)^{* * *}$ & 39.44 & $(13.88)^{* * *}$ \\
\hline No. of obs. & \multicolumn{2}{c}{199} & 95 & 96 \\
R square & 0.77 & 0.61 & 0.53 \\
\hline
\end{tabular}

Notes: (1) Standardized coefficients are reported and numbers in parentheses are t-values. (2) District fixed effects are included in all of the three models. In the regressions of market wages, year dummies (the reference period is 1990) are included in order to control fluctuation in prices.

(3) The units of dependent variables are 1,000 metric tons (rice production) and rupees (market wages).

(4) Agricultural and non-agricultural wages are the annual average daily wages paid to plowmen and carpenters, respectively. 
Table 4: Summary Statistics of Regression Variables

\begin{tabular}{|c|c|c|c|c|c|}
\hline Variable & Unit & Mean & Std. Dev. & Min. & Max. \\
\hline \multicolumn{6}{|c|}{ Dependent variables: Labor hour shares $\left(\ell_{j}\right)$} \\
\hline (a) Self-emp., agriculture & $\%$ & 44.43 & 36.21 & 0 & 100 \\
\hline (b) Wage work, agric. (cash) & $\%$ & 5.59 & 15.60 & 0 & 100 \\
\hline (c) Wage work, agric. (in-kind) & $\%$ & 6.74 & 16.77 & 0 & 100 \\
\hline (d) Wage work, non-agric. & $\%$ & 25.50 & 32.38 & 0 & 100 \\
\hline (e) Self-emp., non-agric. & $\%$ & 17.75 & 28.98 & 0 & 100 \\
\hline \multicolumn{6}{|c|}{ Explanatory variables: Household characteristics $(X)$} \\
\hline Land owned ${ }^{(1)}$ & acre & 2.71 & 4.76 & 0 & 93 \\
\hline Irrigation ratio ${ }^{(1)}$ & $\%$ & 80.00 & 32.74 & 0 & 100 \\
\hline Agric. capital & Rs. & 7367.34 & 31149.75 & 0 & 373600 \\
\hline Livestock & Rs. & 7228.88 & 9707.77 & 0 & 150000 \\
\hline Education $^{(2)}$ & year & 3.51 & 3.59 & 0 & 18.5 \\
\hline Working-age males & person & 1.89 & 1.17 & 0 & 8 \\
\hline Working-age females & person & 1.71 & 1.06 & 0 & 7 \\
\hline Non-working-age members & person & 3.06 & 2.17 & 0 & 17 \\
\hline Dummy for land owner ${ }^{(1)}$ & - & 0.95 & & & \\
\hline \multicolumn{6}{|c|}{ Caste dummies ('Upper' as the reference category) } \\
\hline Middle & - & 0.02 & & & \\
\hline Agric.-based backward & - & 0.32 & & & \\
\hline Other backward & - & 0.18 & & & \\
\hline Scheduled & - & 0.22 & & & \\
\hline Muslim upper & - & 0.04 & & & \\
\hline Muslim backward & - & 0.04 & & & \\
\hline \multicolumn{6}{|c|}{ Explanatory variables: Aggregate risk factors $\left(\sigma_{a}\right)$} \\
\hline $\mathrm{CV}$ of rainfall ${ }^{(3)}$ & - & 0.29 & 0.07 & 0.13 & 0.39 \\
\hline Rainfall shock ${ }^{(3)}$ & $\mathrm{mm}$ & -25.94 & 64.43 & -166.89 & 57.04 \\
\hline \multicolumn{6}{|c|}{ Explanatory variables: Village characteristics } \\
\hline Irrigation indicator $^{(4)}$ & - & 3.80 & 1.19 & 1 & 5 \\
\hline Distance to facilities & $\mathrm{km}$ & 5.97 & 3.61 & 0.5 & 20 \\
\hline Ratio of landless & $\%$ & 38.77 & 21.19 & 0 & 99 \\
\hline Road indicator ${ }^{(4)}$ & - & 2.75 & 0.99 & 1 & 4 \\
\hline Electricity dummy & - & 0.54 & & & \\
\hline Agric. wage & Rs. & 24.62 & 7.31 & 7 & 40 \\
\hline Non-agric. wage & Rs. & 64.68 & 13.90 & 20 & 99 \\
\hline
\end{tabular}

Note: (1) The sample comprises farm households, including pure tenant farmers who do not own land. 'Land owned' is the size of farmland owned by the household. 'Dummy for land owner' is based on 'Land owned'. 'Irrigation ratio' is the size of irrigated land owned by the household divided by 'Land owned'.

(2) 'Education' is the average number of schooling years among working-age adults.

(3) The coefficient of variation ('CV of rainfall') was calculated based on ten-year rainfall data at district-level (1990-1999). 'Rainfall shock' was calculated as the deviation of annual rainfall in 1997, the year of the LSMS survey, from the ten-year average.

(4) 'Irrigation indicator' is an indicator variable based on the village-level irrigation ratio (the size of irrigated farmland divided by the size of total farmland in the village), taking $1(0 \%), 2(1-25 \%)$, $3(26-50 \%), 4(51-75 \%)$, and 5 (above). 'Road indicator' is an indicator variable characterizing the main road in the village, taking 1 (trail), 2 (dirt road), 3 (paved road), and 4 (tar-paved road). 
Table 5: Determinants of Labor Supply

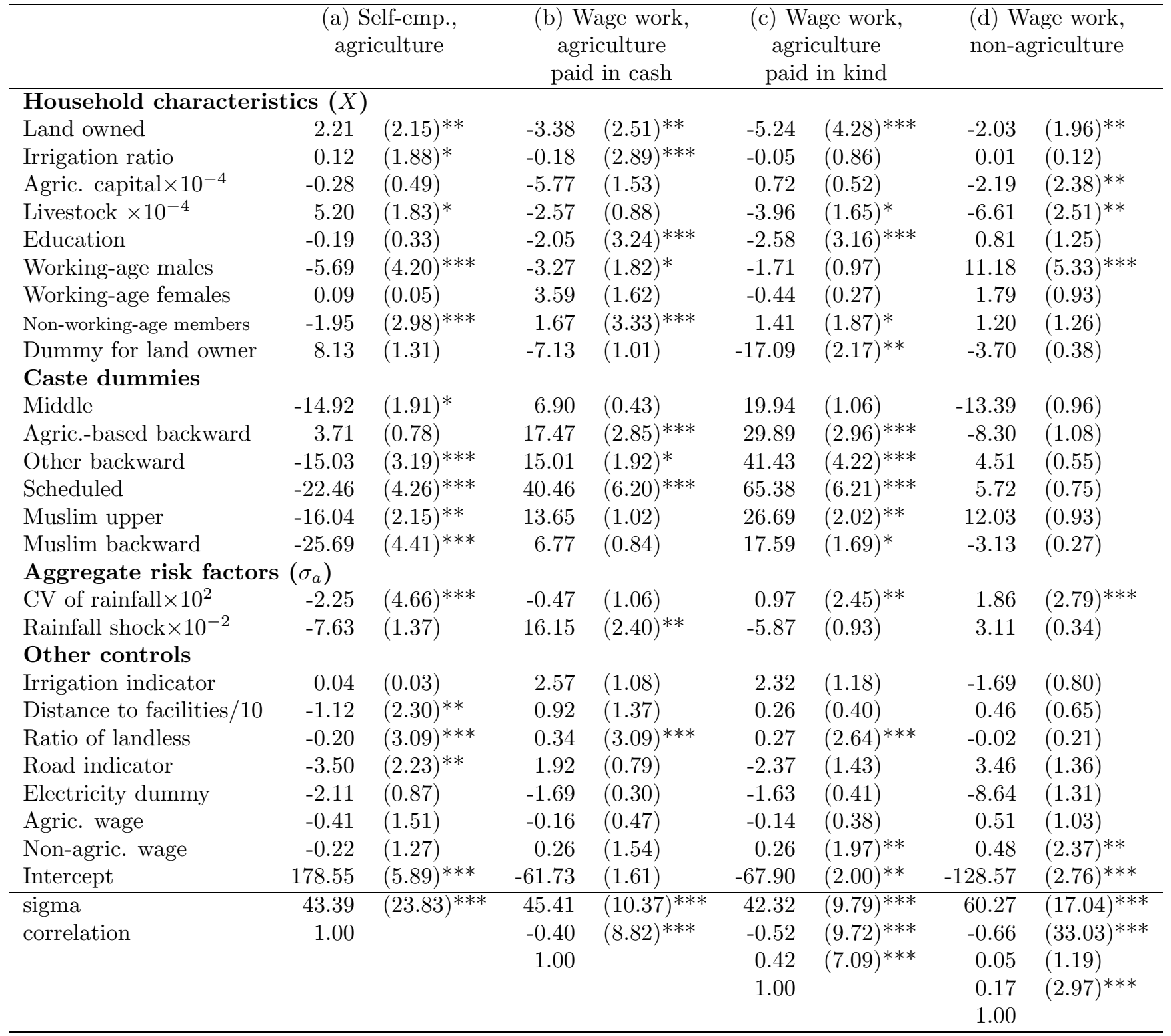

Note: (1) Estimated using a multivariate two-limit tobit model (censored at 0 and 100) with GewekeHajvassiliou-Keane (GHK) simulator (No. of draws $=50$ ).

(2) Additional regressors include district characteristics, such as average rainfall, population, density, and literacy rate, and UP state dummy. Coefficient estimates on these variables have been dropped for brevity but are available on request.

(3) Numbers in parentheses are z-values based on clustering-robust standard errors using districts as clusters.

(4) No. of obs. $=1670 ;$ Log-likelihood $=-15219.81$.

(5) $H_{0}$ : no correlation between errors; $L R \chi^{2}(6)=943.29(P$-value $=0.00)$. 
Table 6: Labor Supply Simulation

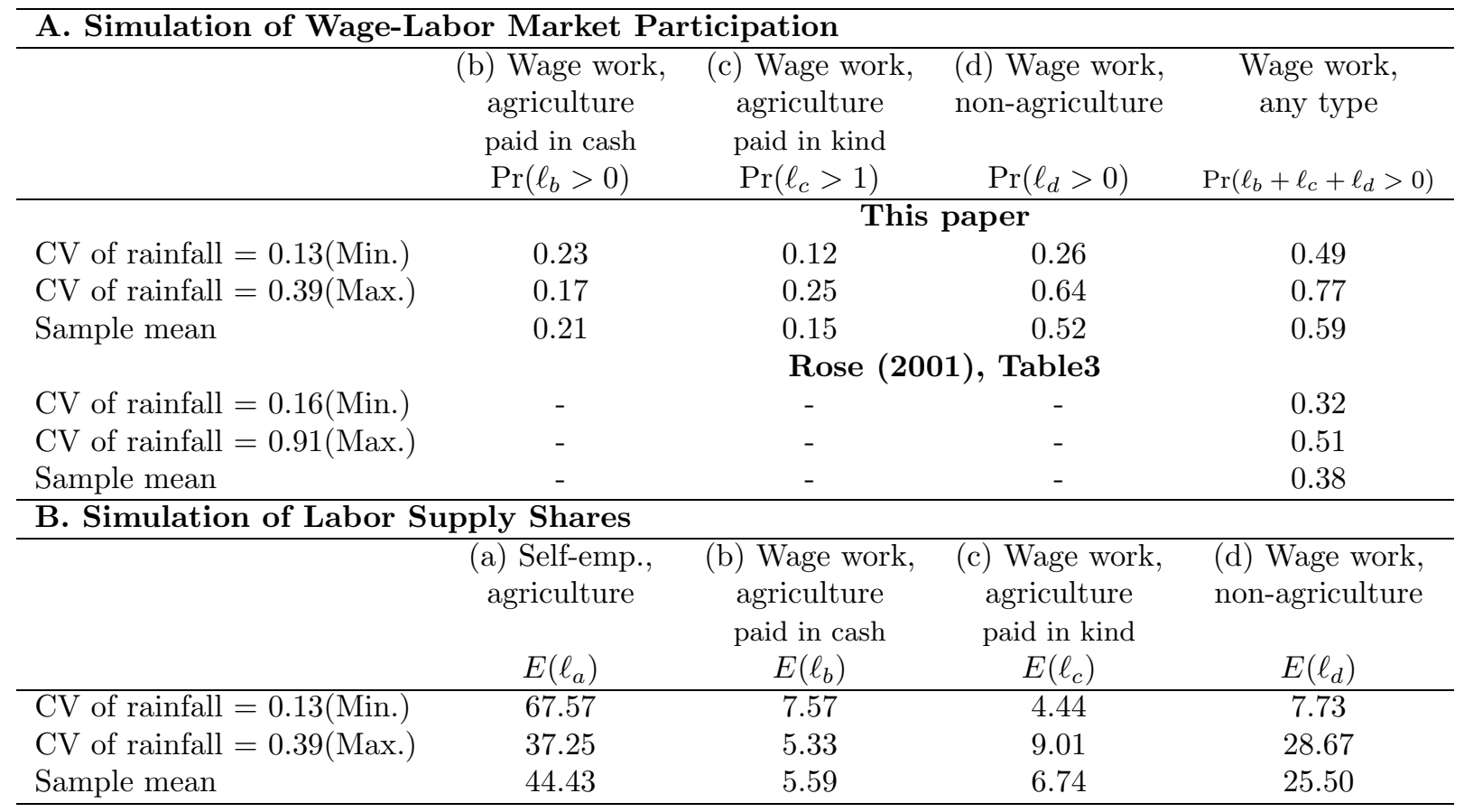

Note: $(1) \operatorname{Pr}\left(\ell_{j}>0\right)=\operatorname{Pr}\left(0<\ell_{j}<100\right)+\operatorname{Pr}\left(\ell_{j}=100\right)$ and $E\left(\ell_{j}\right)=\operatorname{Pr}\left(0<\ell_{j}<100\right) \times E\left(\ell_{j} \mid 0<\right.$ $\left.\ell_{j}<100\right)+100 \times \operatorname{Pr}\left(\ell_{j}=100\right)$. See Appendix III for the simulation procedure. 
Table 7: Specification Tests for the Labor Supply Mode

\begin{tabular}{|c|c|c|c|c|}
\hline & $\begin{array}{l}\text { (a) Self-emp., } \\
\text { Agriculture }\end{array}$ & $\begin{array}{l}\text { (b) Wage work, } \\
\text { agriculture } \\
\text { paid in cash }\end{array}$ & $\begin{array}{l}\text { (c) Wage work, } \\
\text { agriculture } \\
\text { paid in kind }\end{array}$ & $\begin{array}{l}\text { (d) Wage work, } \\
\text { non-agriculture }\end{array}$ \\
\hline \multicolumn{5}{|c|}{ Without any restriction (Table 5) } \\
\hline $\mathrm{CV}$ of rainfall $\times 10^{2}$ & $-2.25(4.66)^{* * *}$ & $(1.06)$ & $(2.45)^{* *}$ & $(2.79)^{* * *}$ \\
\hline Rainfall shock $\times 10^{-2}$ & $-7.63 \quad(1.37)$ & $(2.40)^{* *}$ & $(0.93)$ & $(0.34)$ \\
\hline \multicolumn{5}{|c|}{ Log-likelihood $=-15219.81$} \\
\hline \multicolumn{5}{|c|}{ With a restriction that all coefficients in equations $(b)$ and $(c)$ are equal. } \\
\hline $\mathrm{CV}$ of rainfall $\times 10^{2}$ & $-2.25(4.46)^{* * *}$ & 0.43 & $(1.30)$ & $(2.67)^{* * *}$ \\
\hline Rainfall shock $\times 10^{-2}$ & $-7.67 \quad(1.35)$ & 2.46 & $(0.41)$ & $(0.38)$ \\
\hline \multicolumn{5}{|c|}{ Log-likelihood $=-15254.67 . H_{0}:$ the restricted model is true; $L R \chi^{2}(29)=69.73(P$-value $=0.00)$} \\
\hline \multicolumn{5}{|c|}{ With a restriction that all coefficients in equations $(b),(c)$, and $(\mathrm{d})$ are equal. } \\
\hline $\mathrm{CV}$ of rainfall $\times 10^{2}$ & $-2.02(5.04)^{* * *}$ & & $0.86 \quad(3.38) * * *$ & \\
\hline Rainfall shock $\times 10^{-2}$ & $-7.10 \quad(1.50)$ & & $1.96 \quad(0.37)$ & \\
\hline \multicolumn{5}{|c|}{ Log-likelihood $=-15254.67, H_{0}:$ the restricted model is true; $L R \chi^{2}(58)=329.99(P$-value $=0.00)$} \\
\hline
\end{tabular}

Note: (1) Estimated using a multivariate two-limit tobit model (censored at 0 and 100) with GewekeHajvassiliou-Keane (GHK) simulator (No. of draws $=50$ ).

(2) All regressions are implemented with other variables included, such as household, village, and district characteristics. Coefficient estimates on these variables have been dropped for brevity but are available on request.

(3) Numbers in parentheses are z-values based on clustering-robust standard errors using districts as clusters. 
Table A.1: Robustness Checks

\begin{tabular}{|c|c|c|c|c|c|c|c|c|}
\hline & \multicolumn{6}{|c|}{ Multivariate tobit } & \multirow{2}{*}{\multicolumn{2}{|c|}{$\begin{array}{c}\text { Equation-by- } \\
\text { equation tobit } \\
(4)\end{array}$}} \\
\hline & & (1) & & $(2)$ & & $(3)$ & & \\
\hline \multicolumn{9}{|c|}{ (a) Self-employment, agriculture } \\
\hline $\mathrm{CV}$ of rainfall $\times 10^{2}$ & -1.37 & $(3.17)^{* * *}$ & -1.41 & $(3.06)^{* * *}$ & -2.25 & $(4.66)^{* * *}$ & -2.36 & $(4.86)^{* * *}$ \\
\hline Rainfall shock $\times 10^{-2}$ & -7.14 & $(1.49)$ & -5.89 & $(0.97)$ & -7.63 & $(1.37)$ & -7.82 & $(1.44)$ \\
\hline \multicolumn{9}{|c|}{ (b) Wage work, agriculture paid in cash } \\
\hline $\mathrm{CV}$ of rainfall $\times 10^{2}$ & -0.47 & $(1.04)$ & -0.25 & $(0.66)$ & -0.47 & $(1.06)$ & -0.60 & $(1.22)$ \\
\hline Rainfall shock $\times 10^{-2}$ & 11.22 & $(2.00)^{* *}$ & 14.40 & $(2.11)^{* *}$ & 16.15 & $(2.40)^{* *}$ & 14.60 & $(2.15)^{* *}$ \\
\hline \multicolumn{9}{|c|}{ (c) Wage work, agriculture paid in kind } \\
\hline $\mathrm{CV}$ of rainfall $\times 10^{2}$ & 0.67 & $(1.08)$ & 0.97 & $(2.07)^{* *}$ & 0.97 & $(2.45)^{* *}$ & 0.57 & $(1.33)$ \\
\hline Rainfall shock $\times 10^{-2}$ & -12.56 & $(2.12)^{* *}$ & -7.15 & $(1.15)$ & -5.87 & $(0.93)$ & -6.62 & $(1.05)$ \\
\hline \multicolumn{9}{|c|}{ (d) Wage work, non-agriculture } \\
\hline $\mathrm{CV}$ of rainfall $\times 10^{2}$ & 0.80 & $(1.73)^{*}$ & 0.98 & $(1.91)^{*}$ & 1.86 & $(2.79) * * *$ & 1.84 & $(2.79)^{* * *}$ \\
\hline Rainfall shock $\times 10^{-2}$ & -0.71 & $(0.09)$ & -1.61 & $(0.18)$ & 3.11 & $(0.34)$ & 2.51 & $(0.28)$ \\
\hline Village characteristics & \multicolumn{2}{|c|}{ No } & \multicolumn{2}{|r|}{ Yes } & \multicolumn{2}{|r|}{ Yes } & \multicolumn{2}{|c|}{ Yes } \\
\hline District characteristics & \multicolumn{2}{|r|}{ No } & \multicolumn{2}{|c|}{ No } & \multicolumn{2}{|c|}{ Yes } & \multicolumn{2}{|c|}{ Yes } \\
\hline Log-likelihood & \multicolumn{2}{|c|}{-15300.00} & \multicolumn{2}{|c|}{-15262.17} & \multirow{2}{*}{\multicolumn{2}{|c|}{$\begin{array}{c}-15219.81 \\
-\end{array}$}} & \multicolumn{2}{|c|}{-15691.45} \\
\hline$L R \chi^{2}(P$-value $)$ & 160.37 & $(0.00)$ & 84.73 & $(0.00)$ & & & 943.29 & $(0.00)$ \\
\hline
\end{tabular}

Notes: (1) All regressions are implemented with other variables included, such as household characteristics, district average rainfall and UP state dummy. Coefficient estimates on these variables have been dropped for brevity but are available on request.

(2) Numbers in parentheses are z-values based on clustering-robust standard errors using districts as clusters. 
Figure A.1: An Example of the Optimal Labor Supply

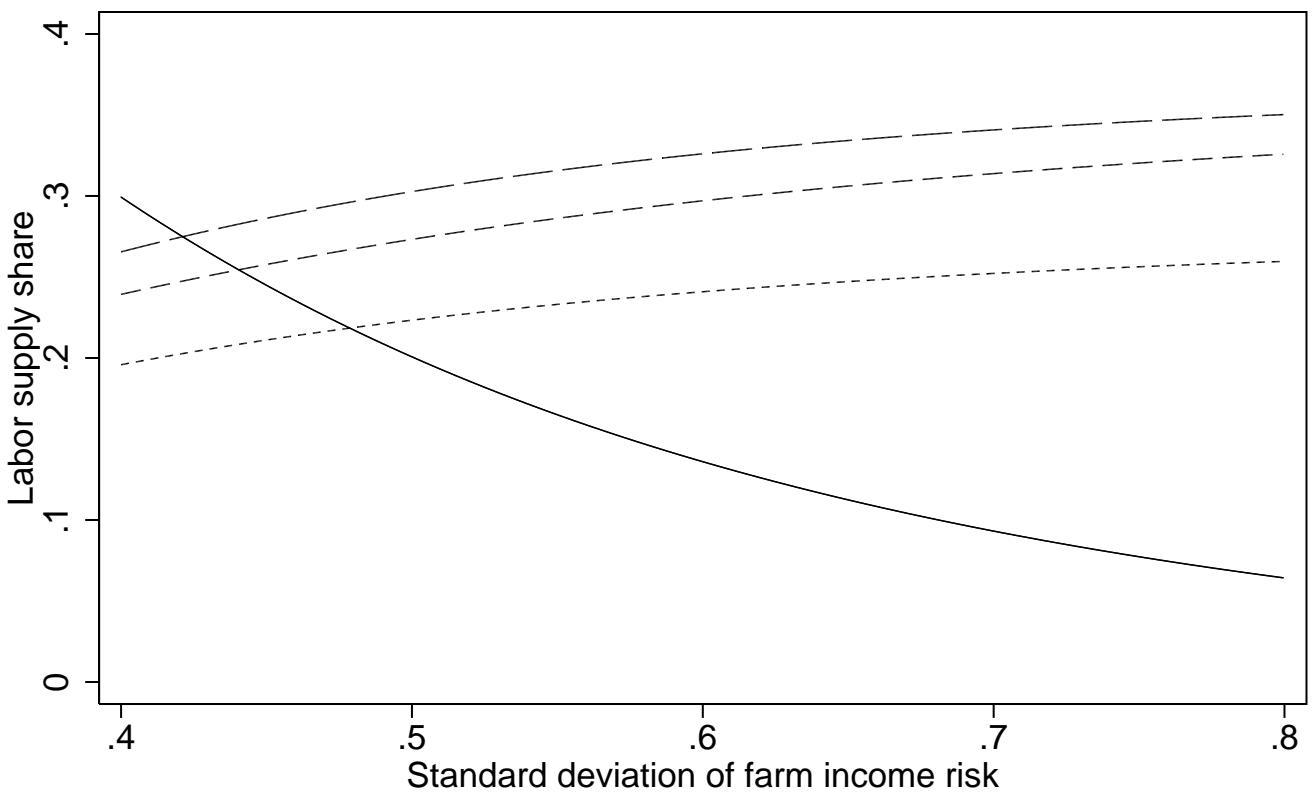
(a) agric. self-emp.
(b) agric. cash wage work
(c) agric. in-kind wage work
(d) non-agric. wage work 